\title{
Mechanisms of Tactile Sensory Phenotypes in Autism: Current Understanding and Future Directions for Research
}

\author{
Melanie D. Schaffler ${ }^{1} \cdot$ Leah J. Middleton $^{1} \cdot$ Ishmail Abdus-Saboor $^{1}$
}

Published online: 5 December 2019

(C) The Author(s) 2019

\begin{abstract}
Purpose of Review This review aims to summarize the current body of behavioral, physiological, and molecular knowledge concerning tactile sensitivity in autism spectrum disorder (ASD), with a focus on recent studies utilizing rodent models.

Recent Findings Mice with mutations in the ASD-related genes, Shank3, Fmr1, UBE3A, and Mecp2, display tactile abnormalities. Some of these abnormalities appear to be caused by mutation-related changes in the PNS, as opposed to changes in the processing of touch stimuli in the CNS, as previously thought. There is also growing evidence suggesting that peripheral mechanisms may contribute to some of the core symptoms and common comorbidities of ASD. Researchers are therefore beginning to assess the therapeutic potential of targeting the PNS in treating some of the core symptoms of ASD.

Summary Sensory abnormalities are common in rodent models of ASD. There is growing evidence that sensory hypersensitivity, especially tactile sensitivity, may contribute to social deficits and other autism-related behaviors.
\end{abstract}

Keywords Autism $\cdot$ Somatosensation $\cdot$ Tactile deficits $\cdot$ Peripheral nervous system $\cdot$ Touch $\cdot$ Pain

\section{Introduction}

Autism spectrum disorder (ASD) is a prevalent neurodevelopmental disorder characterized by social deficits and stereotyped repetitive behaviors [1]. In addition to these core features of autism, researchers have reported that approximately $95 \%$ of individuals with ASD exhibit sensory abnormalities, with $\sim 60 \%$ displaying altered tactile sensitivity [2]. Some individuals injure themselves by head banging, skin picking, and self-biting [3, 4], though the role of pain sensitivity in self-injury is unclear [3,5-7]. Others display exaggerated responses to touch and pain [8-12]. Some individuals will simultaneously display hypersensitivity to some stimuli and hyposensitivity to others, often depending on the context [13-16]. For example, individuals may report hating hugs, while seeking out deep tactile pressure in other ways [17]. While it is possible that the social component of hugs is what

This article is part of the Topical Collection on Autism Spectrum Disorders

Ishmail Abdus-Saboor

ishmail@sas.upenn.edu

1 Department of Biology, University of Pennsylvania, Philadelphia, PA 19104, USA some individuals find repulsive, the reasons why individuals may display both hypo- and hypersensitivity in a variety of situations are not well understood.

Compared with research on the core symptoms of autism, little work has been done investigating the mechanisms behind the tactile abnormalities associated with ASD. However, these tactile abnormalities may very well contribute to some of the core symptoms. For example, hypersensitivity of peripheral neurons may contribute to avoidance of social touch, a common behavioral phenotype in individuals with ASD [18, 19]. Hyposensitivity in the peripheral nervous system may result in an inadequate amount of touch information reaching the brain, causing individuals to be indifferent to social touch. Understanding the causes and effects of somatosensory differences is therefore imperative to understanding the etiology of the disorder and its symptoms. We will review the recent literature on tactile and pain sensitivity in ASD, focusing on studies using genetic rodent models of ASD, as rodent models allow us to directly assess the physiological and behavioral effects of specific autism-related genetic mutations in a controlled environment. Additionally, having the complete genetic and single nucleotide polymorphism (SNP) maps in preclinical rodent models permits a faster translation of research findings in terms of linking a genetic variant with a specific ASDlike phenotype. Lastly, as emerging technologies such as 
CRISPR/Cas9 permit precise modification of virtually any genome including rodents, researchers will increasingly have the ability to model human ASD-related disease alleles in mouse models while testing for ASD phenotypes in behaving mice [20].

\section{The Contribution of Sensory Deficits to Autism}

The sense of touch is essential for sensorimotor control and exploration of our environment. Touch is also a major component of social interactions and the formation of relationships. Social touch, especially during development, can have long-term positive effects across species. Touch communication between mothers and infants improves affect and reduces cortisol reactivity $[21,22]$. Premature infants isolated in incubators who receive $45 \mathrm{~min}$ of touch daily score higher on cognitive and motor tests at 6 months [23, 24]. Mothers who not only touch their infants but also rock them induce a calming response in the infant and interestingly; this calming behavior induced by maternal carrying and moving of offspring is recapitulated in mice [25]. The mom's induction of the calming response in neonatal mice by retrieving and walking with the pups is dependent upon tactile stimulation, with an additional input from vestibular-proprioceptive input [25]. Additionally, rats that received more maternal licking and grooming as pups have reduced responses to stress and increased exploratory behavior in a novel environment [26, 27]. Given the importance of gentle affective touch in development, differences in somatosensory processing in ASD may be responsible for some aspects of autism-related phenotypes. Our knowledge of different populations of touch neurons and their projections in the brain provides direction on where we might begin this research.

In the hairy skin, several low-threshold mechanoreceptors (LTMRs) wrap around hair follicles to mediate the sense of innocuous touch. Of the $\mathrm{A} \beta, \mathrm{A} \delta$, and $\mathrm{C}$ subtypes of LTMRs, C-LTMRs are unmyelinated, found only in hairy skin, and are optimally tuned to stroking of skin at rates that are deemed pleasurable and at temperatures near those of human skin [28-32]. Further, firing frequency of C-LTMRs positively correlates with psychological rating of touch "pleasantness" [29, 33]. C-LTMRs are therefore implicated in affective social touch (i.e. touch between a parent and a child or between intimate partners) in humans. The brain regions implicated in processing C-LTMR-mediated touch (e.g. insular cortex) are also implicated in social perception and social cognition, processes in which individuals with ASD often display deficits $[1,29,30,34]$. Further, there is a striking association between social abilities, touch preferences, and brain mechanisms for processing affective touch [35]. Individuals with more autism-related traits have reported an aversion to social touch, complementing a negative correlation between autismrelated traits and brain responses to affective touch [35]. Furthermore, participants with more autistic traits exhibited less activation to C-LTMR-mediated gentle touch in the "social brain," a set of brain regions that have evolved to support social cognition including the amygdala, orbitofrontal cortex, and temporal cortex $[35,36]$. These results suggest that somatosensory deficits and sociability deficits are linked, but only via correlational evidence and without an analysis of how autism-related genes may play a role in these deficits. There are several genetic rodent models of ASD that exhibit aberrant tactile processing, allowing us to begin to explore how autism-related genes may contribute to the ASD phenotype by impacting the somatosensory system.

\section{Perception of Tactile Stimulation: From Skin to Brain}

In order to adequately discuss the current research on the somatosensory system in autism models, we must first gain an appreciation for how our nervous systems encode somatosensory stimuli. The somatosensory system provides mammals with the capacity to explore their environment and form meaningful social bonds via tactile stimulation of the skin, while remaining safe from physical harm. In the peripheral nervous system (PNS), dorsal root ganglion (DRG) and trigeminal ganglion (TG) pseudo-unipolar primary afferent neurons project one sensory neurite to the skin and another to the dorsal horn of the spinal cord, thus connecting the periphery to the central nervous system (CNS) (Fig. 1). The multitude of DRG and TG neurons that respond to not only tactile stimulation but also thermal and itch stimuli has distinct nerve fiber diameters, conduction velocities, gene expression profiles, sensory ending morphologies, depth in the skin, rate of adaption to sustained stimulus application, and unique innervation patterns in both the skin and spinal cord. In this review, we will focus primarily on encoding of cutaneous stimuli in the periphery in the context of autistic phenotypes.

The perception of touch is sensed in the skin by four types of low-threshold mechanoreceptive sensory neurons (LTMRs) that terminate in elaborate end-organ structures composed of intertwined wrappings of epithelial or Schwann cells. As mentioned briefly above, LTMRs are subdivided by functional properties such as soma size and gene expression patterns, into classes known as $\mathrm{A} \delta$-, $\mathrm{A} \beta-$, and C-LTMRs. In general, large-diameter, heavily myelinated neurons ( $\mathrm{A} \beta$ fibers) respond to touch, while smaller diameter, lightly, or unmyelinated neurons (A $\delta$ or $\mathrm{C}$ fibers) respond to pain. However, A $\delta$-LTMRs and $\mathrm{C}$ LTMRs are exceptions to this generalization, as they are subsets of intermediate- and small-diameter neurons that respond to touch rather than pain. $\mathrm{A} \delta$ - and $\mathrm{A} \beta$-LTMRs 
Fig. 1 Pseudo-unipolar sensory neurons in the dorsal root ganglion project one sensory neurite to the skin and another to the dorsal horn of the spinal cord. Discrete subtypes of primary sensory neurons detect noxious and innocuous mechanical stimuli and ultimately activate distinct projection neurons which deliver somatosensory information to the brain. However, interneurons in the spinal cord add complexity to this circuit: touch neurons do have input to pain projection pathways, but local interneurons keep this under strong inhibition under healthy conditions

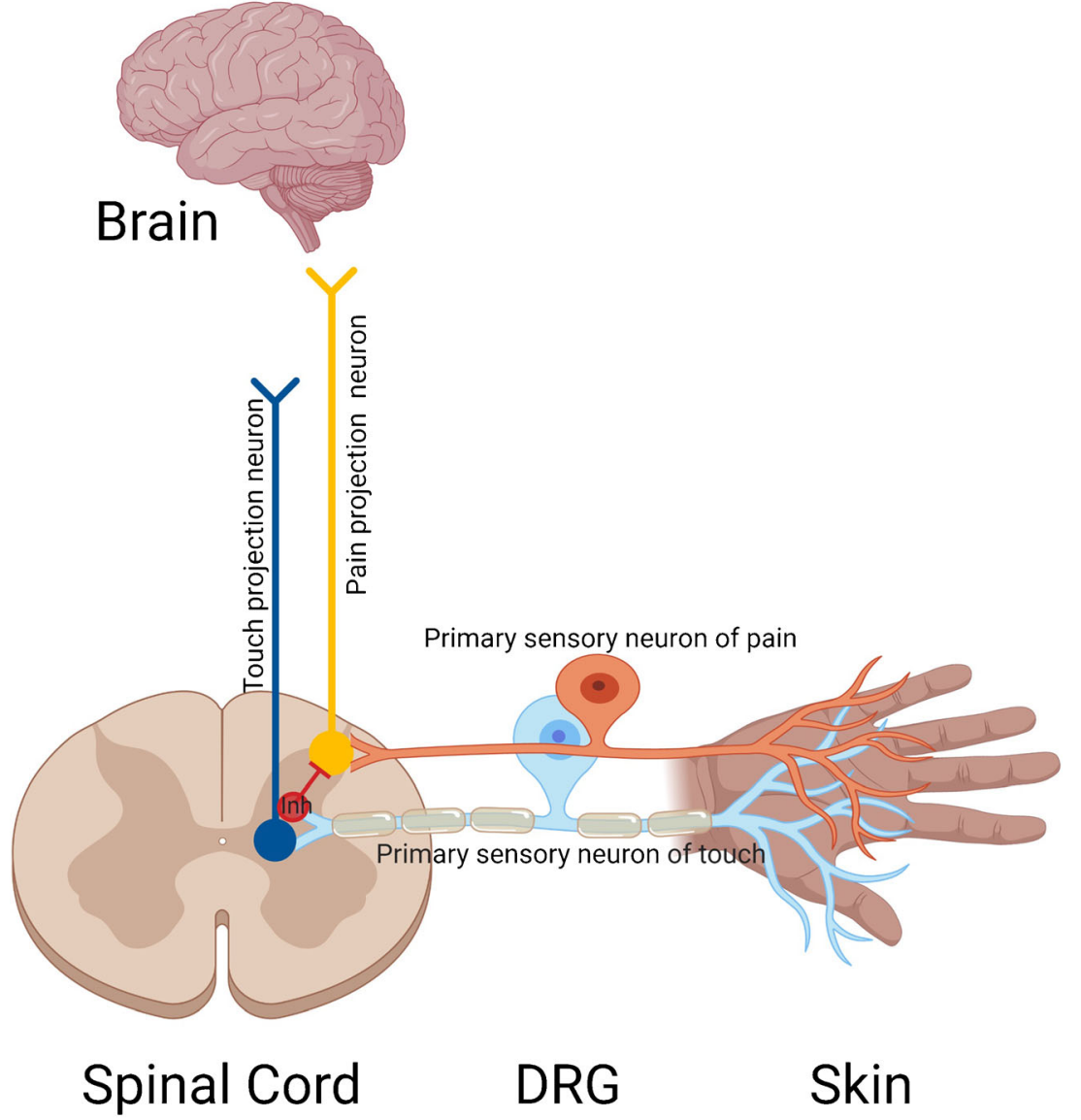

encode discriminative touch, which is the ability to detect fine structural details of an object with our fingers, for example [37, 38]. A second type of touch, known as affective touch, occurs in a social context typically between friends, lovers, and family and is encoded by C-LTMR neurons [39-42]. In contrast to the perception of touch that predominantly utilizes special end organs, painful, potentially damaging stimuli are generally sensed by "nociceptors" which innervate the skin with free nerve terminal endings, devoid of attachment to any sensory end-organ [43]. A recent groundbreaking study however has updated our classification of nociceptive sensory cells in the skin by demonstrating in mice that a specialized Schwann cell associated with nociceptors forms a glioneuro end-organ structure that is capable of transducing mechanical and thermal noxious stimulation [44].

The spinal cord serves as the relay station between the skin and brain, and is the first location where the body prioritizes how much touch versus pain information reaches the brain and our conscious awareness. Interneurons in the dorsal horn of the spinal cord control the crosstalk between "touch" and "pain" labelled lines from the periphery organized in different laminae of the spinal cord dorsal horn [45-52] (Fig. 1). Touch information from the skin typically enters in deeper spinal laminae within the dorsal horn, while nociceptive information enters in more superficial spinal laminae of the dorsal horn. Touch signals are sent to the brain directly from some A $\beta$-LTMRs to the gracile nucleus of the medulla [53], or indirectly from projection neurons that ascend ipsilaterally to the brainstem dorsal column nuclei [54]. Pain signals are sent to the brain from the spinal cord from longrange projection neurons that first cross over to the opposite side of the spinal cord followed by ascending directly to the brain in five major ascending pathways termed spinothalamic, spinoreticular, spinomesencephalic, cervicothalamic, and spinohypothalamic [55]. Extending from the thalamus, tactile information is encoded in the somatosensory cortex in the post central gyrus just three synapses away from receptors in the skin. In regard to pain, while the thalamocortical projections are important for the discriminatory components of the pain response, the negative valence state associated with pain is encoded in brain structures that receive thalamic input such as the basolateral amygdala and anterior cingulate cortex [56, 57].

The findings described above provide a basis for investigators to research how the peripheral nervous system and various ascending pathways may be altered in ASD. With the ability to target, observe, and manipulate specific populations of touch or pain neurons in mouse models, researchers have begun to study the PNS in the context of autism. 


\section{Rodent Models Relevant to Syndromic ASD With a Somatosensory Phenotype}

Animal models are highly useful in understanding the contribution of genetic mutations to tactile abnormalities. With rodent models, we can apply different noxious and innocuous stimuli in a controlled setting and objectively assess behavioral and physiological responses. Rodent models also allow us to control for any environmental influences that can contribute to an ASD phenotype. Further, neural mechanisms underlying sensory processing are well-conserved between humans and rodents, and several genetic rodent models relevant to idiopathic and syndromic forms of ASD display abnormal sensitivity to somatosensory stimuli (Table 1) [58].

For example, mice with a deletion of the entire $\mathrm{SH} 3$ and multiple ankyrin repeat domains 3 (SHANK3) protein coding sequence display behavioral phenotypes that resemble the major features of SHANK3-related ASD, including pain sensitivity [59, 60]. SHANK3, like other members of the SHANK gene family, is a scaffold protein that plays a role in synapse formation and dendrite maturation [61]. It is expressed in both human and mouse DRG neurons, including LTMRs [62, 63]. The gene is highly implicated in ASD, with mutations occurring in $\sim 2 \%$ of all patients [64]. Approximately $77 \%$ of individuals with Phelan-McDermid syndrome, a genetic condition with symptoms of ASD and frequently co-occurring with an ASD diagnosis, in which the entire SHANK3 gene is deleted, demonstrates decreased pain sensitivity, suggesting that the gene plays a role in pain processing [65]. Han et al. found that Shank3 is broadly expressed in mouse DRG neurons and their terminals in the spinal cord. Strikingly, they also found that Shank3 plays a role in pain transduction via regulating transient receptor potential ion channel subtype V1 (TRPV1), a capsaicin receptor that regulates heat transduction and is expressed in C-fiber nociceptive neurons [60]. The currents recorded from TRPV1 channels in DRG neurons were reduced in the Shank3 mutant mice, complementing the impaired heat hyperalgesia observed behaviorally in these knockout mice. They also found that haploinsufficiency of SHANK3 causes defects in TRPV1 function in both mouse and human DRG neurons. These results indicate that SHANK3 mutations can alter the function of peripheral neurons, suggesting a possible peripheral mechanism for somatosensory deficits in ASD.

Fragile X syndrome (FXS) is another common syndromic form of ASD ( $2 \%$ of ASD cases), with symptoms including intellectual disability, repetitive behaviors, social deficits, increased anxiety, and abnormal sensory processing [66]. FXS is caused by a mutation in the fragile $\mathrm{X}$ mental retardation 1 (FMR1) gene, which codes for fragile $\mathrm{X}$ mental retardation protein (FMRP). FMRP is implicated in synaptic protein synthesis and synaptic plasticity [67, 68]. Fmrl knockout mice display several behavioral deficits similar to human FXS symptoms including hypersensitivity to tactile stimuli $[69,70]$. While investigating whether these tactile deficits were due to abnormalities in the somatosensory cortex, He et al. found that the proportion of layer $2 / 3$ neurons in the barrel cortex (a region of the somatosensory cortex) that respond in a time locked manner to whisker stimulation is $45 \%$ lower in Fmrl $\mathrm{KO}$ mice, and that $\mathrm{L} 2 / 3$ neuronal activity in the $\mathrm{KO}$ mice shows a lack of adaptation to repetitive whisker stimulation [69]. These results suggest that it is a lack of neuronal adaption to tactile stimuli in the somatosensory cortex that contributes to the sensory overactivity in FXS, and perhaps in other ASDs. More work is needed to determine whether the loss of adaptation to tactile stimuli originates in the periphery and projects to the somatosensory cortex where the differences were observed, or whether the adaptation deficit occurs solely in the brain.

Another syndromic form of ASD is Angelman syndrome (AS), a severe neurodevelopmental disorder caused by a mutation or deletion of the maternal UBE3A allele [71]. The ubiquitin-protein ligase E3A (UBE3A) gene codes for the

Table 1 Selected studies of autism-related genes and how they contribute to a somatosensory phenotype

\begin{tabular}{|c|c|c|c|c|c|}
\hline Study & Year & $\begin{array}{l}\text { ASD- } \\
\text { related } \\
\text { gene }\end{array}$ & Tactile behavioral phenotype & Molecular/physiological mechanism & $\begin{array}{l}\text { Source of } \\
\text { phenotype }\end{array}$ \\
\hline Han et al. & 2016 & SHANK3 & $\begin{array}{l}\text { Shank3 knockout } \rightarrow \text { impaired heat } \\
\text { hyperalgesia }\end{array}$ & SHANK3 regulates TRPV1 function and expression & Peripheral \\
\hline He et al. & 2017 & FMR1 & $\begin{array}{l}\text { Fmr1 knockout } \rightarrow \text { hypersensitivity to tactile } \\
\text { stimuli }\end{array}$ & $\begin{array}{l}\text { Layer } 2 / 3 \text { neurons in barrel cortex show reduced re- } \\
\text { sponse to whisker stimulation }\end{array}$ & Central \\
\hline McCoy et al. & 2017 & UBE3A & $\begin{array}{l}\text { Whole genomic deletion of maternal } \\
\text { Ube } 3 \mathrm{a} \rightarrow \text { increased sensitivity to noxious } \\
\text { heat and mechanical stimuli }\end{array}$ & $\begin{array}{l}\text { DRG-specific maternal deletion of Ube } 3 a \rightarrow \text { normal } \\
\text { sensitivity }\end{array}$ & Central \\
\hline $\begin{array}{l}\text { Bhattacherjee } \\
\text { et al. }\end{array}$ & 2017 & MECP2 & $\begin{array}{l}\text { Mecp2 knockout } \rightarrow \text { hypersensitivity to } \\
\text { mechanical stimuli }\end{array}$ & $\begin{array}{l}\text { Increased nonpeptidergic innervation of cutaneous } \\
\text { targets in Mecp2 knockouts }\end{array}$ & Peripheral \\
\hline Orefice et al. & 2016 & MECP2 & $\begin{array}{l}\text { DRG-specific deletion of } \\
\text { Mecp } 2 \rightarrow \text { abnormalities in touch sensitivity } \\
\text { and cognitive and social deficits }\end{array}$ & $\begin{array}{l}\text { DRG-specific Mecp2 deletion } \rightarrow \text { decreased GABRB3 } \\
\text { in dorsal horn of spinal cord } \rightarrow \text { decreased PSI of } \\
\text { LTMR inputs to CNS }\end{array}$ & Peripheral \\
\hline
\end{tabular}


UBE3A enzyme, which tags proteins with ubiquitin to target them for degradation. UBE3A is expressed on both alleles in most tissues, but the full-length protein is expressed primarily from the maternal allele in the CNS [72-74]. UBE3A displays differential allelic expression because paternal UBE3A is repressed in the CNS by UBE3A-ATS, a long noncoding transcript [75-78]. Little research has been done investigating the expression pattern of UBE3A in the PNS, but parent reports and questionnaires indicate that sensory processing deficits are also common in $\mathrm{AS}$, including slow responses to pain $[79,80]$. McCoy et al. recently found that large-diameter touch neurons in the DRG expressed maternal Ube $3 a$ and paternal Ube3a-ATS, while most small-diameter pain neurons expressed Ube3a on both alleles with little levels of Ube3aATS [81]. In short, touch neurons express Ube3a protein from the maternal allele, similar to the CNS, while pain neurons express the protein from both alleles. Additionally, behavioral responses to noxious stimuli were enhanced in AS model mice, in which there is a deletion of maternal Ube3a. Interestingly, a conditional deletion of maternal Ube3a in only the DRG did not affect responses to painful mechanical stimuli. These data indicate that the enhanced nociceptive responses in AS mice are due to loss of maternal Ube3a in the central and not the peripheral nervous system, suggesting a central mechanism for tactile deficits in AS.

While a loss-of-function mutation in UBE3A underlies Angelman's syndrome, gain-of-function mutations of UBE3A are also associated with autistic features. A central mechanism implicating the autism-liked gene, cerebellin1 (CBLN1), was recently proposed to underlie these UBE3Amediated social deficits $[82,83]$. Krishnan et al. demonstrate that the increase in UBE3A induces a downregulation of CBLN1, and further, that behavioral changes following loss of CBLN1 specifically in ventral tegmental area (VTA) neurons mimic the UBE3A-mediated social deficits. CBLN1 is a synaptic organization protein that, while primarily studied for its role in motor function in the cerebellum, is also implicated in learning deficits through its function in the hippocampus [84-86]. While these findings suggest that a central mechanism explains the CBLN-mediated behavioral features of autism, because peripheral changes in these models are unexplored, a peripheral mechanism cannot be excluded. Highthroughput single-cell RNA sequencing studies reveal that CBLN1 is highly co-expressed in one small subset of DRG neurons that also express mas-related g-protein coupled receptor B4 (MrgprB4) [87, 88]. Interestingly, the MrgprB4-expressing neurons are thought to represent a population of C-LTMRs and therefore are speculated to play a role in social touch [89]. Thus, while the focus for CBLN1 has been central, it remains an interesting possibility that autism-linked CBLN1 deficits also impair sociability by altering sensation of socially relevant tactile stimuli by its function in a subset of C-LTMRs.
Rett syndrome (RTT), another severe autism-associated developmental disorder, is caused by mutation of the X-linked gene, methyl-CpG binding protein 2 (MECP2) [90]. The MECP2 protein regulates protein synthesis by acting as a transcriptional repressor or activator [91]. Interestingly, there is evidence in zebrafish that well-known axon guidance cues Semaphorin 5b (Sema5b) and Roundabout Guidance Receptor 2 (Robo2) are positively regulated by Mecp2 and are needed for innervation of sensory neurons [92]. It is therefore no surprise that individuals with RTT have somatosensory abnormalities, with reports of both insensitivity and elevated pain thresholds [93-95]. While investigating how the MECP2 gene might affect the PNS in mammals, Bhattacherjee et al. found that a rat model of RTT displayed increased pressure and cold sensitivity, hyposensitivity to heat, and interestingly, increased DRG axon outgrowth [96]. Further, MeCP2 knockdown specifically in DRG neurons increases DRG axon outgrowth and causes mechanical hypersensitivity in wild-type rats [96]. These findings suggest that MECP2 plays a major role in regulating peripheral innervation, indicating a peripheral mechanism for the tactile abnormalities seen in RTT.

Rodent models of syndromic ASDs have been a valuable tool in understanding the social, cognitive, and sensory aspects of these neurodevelopmental disorders. While major strides have been made in recent years, we still have a lot to learn about the role that ASD-related genes play in tactile sensitivity, and how tactile sensitivity may contribute to the behavioral symptoms of ASD. The results from the aforementioned MeCP2 and Shank3 studies, along with others, suggest that peripheral mechanisms are responsible for the tactile differences in these disorders (Fig. 2) [60, 96]. Recently, labs have begun to focus on how peripheral mechanisms may contribute to the social and repetitive core symptoms of autism.

\section{The Role of the PNS in Contributing to Behavioral Symptoms of ASD}

The majority of ASD research has focused on brainspecific mechanisms and circuits, with little attention to potential contributions of the PNS to ASD phenotypes. A recent review by Cascio et al. describes in depth how social touch in development is highly important for the formation of secure attachment, cognitive and linguistic development, and social reward [97]. Normal somatosensory functioning during development may therefore be essential for later expression of normal social behaviors. Recent groundbreaking studies by Orefice et al. sought to investigate how mutations in autism-related genes may contribute to tactile sensitivity abnormalities, and how these abnormalities may contribute to an ASD diagnosis [98, 99].

Similar to results from other researchers, Orefice et al. found that mice with mutations in Mecp2, Shank3, Fmr1, and gamma- 
Fig. 2 Examples of how mutations in autism-related genes may contribute to tactile abnormalities. Based on results from Han et al. 2016 [60], Bhattacherjee et al. 2017 [96], and Orefice et al. 2016 [98]

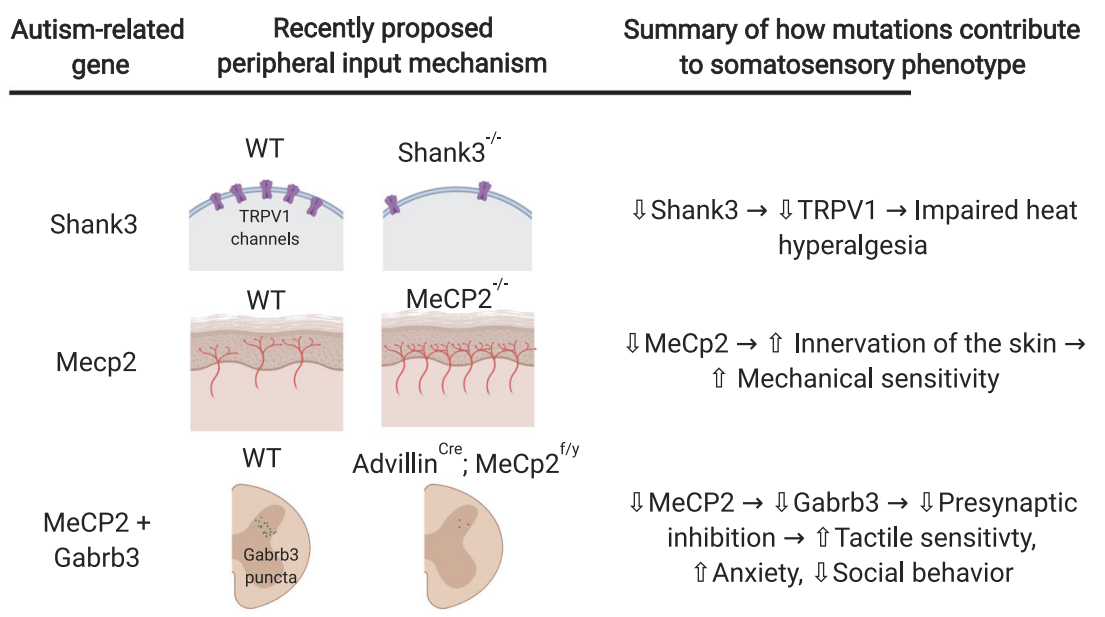

aminobutyric acid receptor subunit beta-3 (Gabrb3) all display altered tactile discrimination and hypersensitivity to gentle touch $[69,96,98,99]$. These mutant models were selected based on their genetic and behavioral similarities to humans with autism. Strikingly, tactile deficits caused by Cre-lox mediated developmental deletion of Mecp2, Gabrb3, or Shank3 specifically in DRG neurons led to behavioral deficits resembling some of the core phenotypes of ASD (anxiety-like behaviors, reduced sociability, and reduced preferences for social novelty) $[98,99]$. Deletion of Mecp 2 and Gabrb3, a GABA A inhibitory receptor subunit, in adult DRG neurons led to similar changes in tactile sensitivity but resulted in more modest social deficits [98]. Deletion of Shank3 at P28, as opposed to earlier in development, also led to tactile abnormalities, and less severe social impairments [99]. These findings suggest that developmental somatosensory dysfunction caused by mutations in autismrelated genes can cause ASD core symptoms. A decrease in the number of parvalbumin-positive $(\mathrm{PV}+)$ neurons in the basolateral amygdala, a brain region involved in anxiety and social behaviors, in mice with DRG-specific Shank3 and Mecp2 mutations suggests a potential mechanism for why periphery-specific mutations of ASD-related genes may result in anxiety behaviors and social deficits [99].

Because deletion of Mecp2 in the DRG led to a decrease in Gabrb3 in the dorsal horn of the spinal cord, the authors proposed a mechanism for how Mecp2 mutations lead to somatosensory abnormalities: reduced presynaptic GABA-mediated inhibition of LTMR inputs to the CNS [98]. In a follow-up study, they also found that large-diameter neurons cultured from Shank3 mutants displayed decreased current mediated by hyperpolarization-activated cyclic nucleotide-gated $(\mathrm{HCN})$ channels and increased excitability compared with neurons harvested from control mice [99]. Together, these findings suggest that there are at least two mechanisms that underlie tactile hypersensitivity in ASD models: GABA- and HCNmediated. Therefore, in attempting to treat tactile or other abnormalities in ASD by targeting the peripheral nervous system, it is unlikely that there will be a one-size-fits-all method.

Orefice et al. have already begun investigating the potential therapeutic benefit of targeting peripheral somatosensory neurons in ASD models [99]. Restoration of Shank3 or Mecp2 in cells below the neck or exclusively in DRG neurons was able to rescue some sensitivity deficits, anxiety-like behavior, and social deficits. Postnatal viral restoration of Gabrb3 in PNS neurons of mice with PNS-specific Mecp2 mutations improved tactile abnormalities, anxiety-like behaviors, social impairments, and PV+ neuron abnormalities in the BLA. Perhaps most strikingly, peripherally restricted pharmacological treatment with a $\mathrm{GABA}_{\mathrm{A}}$ receptor agonist reduced hairy skin hypersensitivity in Shank3, Fmr1, and Cntnap2 mutant mice and a mouse model of maternal immune activation-induced (MIA) ASD. It also improved anxiety-like behaviors, social impairments, and PV+ neuron abnormalities in the BLA in Shank3 and Mecp2 mutant mice without causing sedation. These results suggest a potential novel therapeutic strategy for treating certain ASD-related behaviors.

\section{Conclusion}

Historically, research on the etiology of ASD has focused heavily on the brain, but peripheral mechanisms of ASD are beginning to be uncovered, with growing evidence that somatosensory neurons are dysfunctional and contribute to ASD-related behaviors in a range of ASD models including Mecp2, Gabrb3, Shank3, Cntnap2, and Fmr1 mutants, and MIA models [96, 98, 99]. With evidence that DRG-specific loss of ASD-related genes can lead to changes in brain circuits, particularly the number of PV+ interneurons in the somatosensory cortex and BLA, in addition to ASD-related behaviors, early therapeutic targeting of the PNS could be the future of autism treatment research. 
It is important to note that loss of these ASD-related genes in the PNS has not yet been shown to cause any repetitive behaviors or memory deficits, which are common ASD-related symptoms. It is likely that a combination of mutations in the CNS and the PNS contributes to the full spectrum of behavioral deficits. However, evidence that we can treat multiple symptoms of ASD by targeting the PNS provides a basis for the future of autism therapeutic research. By targeting the PNS, we can circumvent side effects associated with directly manipulating brain circuits, such as sedation, as many of the current FDA-approved drugs that cross the blood-brain barrier do [99-101].

As sensory abnormalities in ASD are not restricted to somatosensation, it is possible that, similar to the findings by Orefice et al. [98, 99], abnormalities in other senses could lead to abnormal social behaviors. For example, auditory hyper- or hyposensitivity could result in deficits in language learning and production. Sensory hypersensitivity may also contribute to other ASD symptoms such as anxiety, hyperarousal and sleep deficits, attention deficits, stereotyped behaviors, and learning disabilities. For example, people have reported fluorescent lights increasing repetitive behaviors or causing tantrums [102]. Further studies are needed to examine how sensory abnormalities may contribute to the ASD-related behaviors, and could ultimately lead to the development of novel approaches to early intervention and treatment.

Acknowledgments We thank members of the Abdus-Saboor lab for helpful comments on this manuscript. The figures were created with Biorender.com.

Funding Information This work was supported by startup funds from the University of Pennsylvania and NIH R00 grant (DE026807).

Open Access This article is licensed under a Creative Commons Attribution 4.0 International License, which permits use, sharing, adaptation, distribution and reproduction in any medium or format, as long as you give appropriate credit to the original author(s) and the source, provide a link to the Creative Commons licence, and indicate if changes were made. The images or other third party material in this article are included in the article's Creative Commons licence, unless indicated otherwise in a credit line to the material. If material is not included in the article's Creative Commons licence and your intended use is not permitted by statutory regulation or exceeds the permitted use, you will need to obtain permission directly from the copyright holder. To view a copy of this licence, visit http://creativecommons.org/licenses/by/4.0/.

\section{References}

Papers of particular interest, published recently, have been highlighted as:

- Of importance

•- Of major importance

1. American Psychiatric Association. Diagnostic and statistical manual of mental disorders (5th ed.). 2013.
2. Tomchek SD, Dunn W. Sensory processing in children with and without autism: a comparative study using the Short Sensory Profile. Am J Occup Ther [Internet]. 2007;61:190-200. Available from: https://doi.org/10.5014/ajot.61.2.190.

3. Furniss F, Biswas AB. Recent research on aetiology, development and phenomenology of self-injurious behaviour in people with intellectual disabilities: a systematic review and implications for treatment. J Intellect Disabil Res [Internet]. John Wiley \& Sons, Ltd (10.1111); 2012;56:453-75. Available from: https://doi.org/ 10.1111/j.1365-2788.2012.01534.x.

4. Ross-Russell M, Sloan P. Autoextraction in a child with autistic spectrum disorder. Br Dent J [Internet]. 2005;198:473-4. Available from: https://doi.org/10.1038/sj.bdj.4812250, 2005.

5. MacLean WE, Tervo RC, Hoch J, Tervo M, Symons FJ. Selfinjury among a community cohort of young children at risk for intellectual and developmental disabilities. J Pediatr [Internet]. 2010;157:979-83. Available from: http://www.sciencedirect. com/science/article/pii/S0022347610004798.

6. Schroeder SR, Oster-Granite M Lou, Berkson G, Bodfish JW, Breese GR, Cataldo MF, et al. Self-injurious behavior: genebrain-behavior relationships. Ment Retard Dev Disabil Res Rev [Internet]. John Wiley \& Sons, Ltd; 2001;7:3-12. Available from: https://doi.org/10.1002/1098-2779(200102)7:1\%3C3::AIDMRDD1002\%3E3.0.CO.

7. Sandman CA, Spence MA, Smith M. Proopiomelanocortin (POMC) disregulation and response to opiate blockers. Ment Retard Dev Disabil Res Rev [Internet]. John Wiley \& Sons, Ltd; 1999;5:314-21. Available from: https://doi.org/10.1002/ (SICI)1098-2779(1999)5:4\%3C314::AID-MRDD9\%3E3.0.CO.

8. Rattaz C, Dubois A, Michelon C, Viellard M, Poinso F, Baghdadli A. How do children with autism spectrum disorders express pain? A comparison with developmentally delayed and typically developing children. Pain [Internet]. 2013;154. Available from: https:// journals.lww.com/pain/Fulltext/2013/10000/How_do_children with_autism_spectrum_disorders.18.aspx

9. Reynolds S, Bendixen RM, Lawrence T, Lane SJ. A pilot study examining activity participation, sensory responsiveness, and competence in children with high functioning autism spectrum disorder. J Autism Dev Disord [Internet]. 2011;41:1496-506. Available from: https://www.ncbi.nlm.nih.gov/pubmed/ 21221753.

10. Elwin M, Ek L, Schröder A, Kjellin L. Autobiographical accounts of sensing in Asperger syndrome and high-functioning autism. Arch Psychiatr Nurs [Internet]. Elsevier; 2012;26:420-9. Available from: https://doi.org/10.1016/j.apnu.2011.10.003.

11. Lane AE, Dennis SJ, Geraghty ME. Brief report: further evidence of sensory subtypes in autism. J Autism Dev Disord [Internet]. 2011;41:826-31. Available from: https://doi.org/10.1007/ s10803-010-1103-y.

12. Ben-Sasson A, Cermak SA, Orsmond GI, Tager-Flusberg H, Carter AS, Kadlec MB, et al. Extreme sensory modulation behaviors in toddlers with autism spectrum disorders. Am J Occup Ther [Internet]. 2007;61:584-92. Available from: https://doi.org/10. 5014/ajot.61.5.584.

13. Brown NB, Dunn W. Relationship between context and sensory processing in children with autism. Am J Occup Ther. 2010.

14. Baranek GT, David FJ, Poe MD, Stone WL, Watson LR. Sensory Experiences Questionnaire: discriminating sensory features in young children with autism, developmental delays, and typical development. J Child Psychol Psychiatry [Internet]. John Wiley \& Sons, Ltd (10.1111); 2006;47:591-601. Available from: https:// doi.org/10.1111/j.1469-7610.2005.01546.x.

15. Dunn W, Myles BS, Orr S. Sensory processing issues associated with Asperger syndrome: a preliminary investigation. Am J Occup Ther [Internet]. 2002;56:97-102. Available from: https://doi.org/ 10.5014/ajot.56.1.97. 
16. Iarocci G, McDonald J. Sensory integration and the perceptual experience of persons with autism. J Autism Dev Disord [Internet]. 2006;36:77-90. Available from: https://doi.org/10. 1007/s10803-005-0044-3.

17. Grandin T, Scariano M. Emergence: labeled autistic. Novato, CA: Arena Press; 1986.

18. Richer J. The social-avoidance behaviour of autistic children. Anim Behav [Internet]. 1976;24:898-906. Available from: http://www. sciencedirect.com/science/article/pii/S0003347276800206.

19. Voos AC, Pelphrey KA, cognitive and K-MD. Autistic traits are associated with diminished neural response to affective touch. Soc Cogn and ... [Internet]. 2012; Available from: https://academic.oup. $\mathrm{com} / \mathrm{scan} /$ article-abstract/8/4/378/1623776 VN - readcube.com.

20. Jiang F, Doudna JA. CRISPR-Cas9 structures and mechanisms. Annu Rev Biophys [Internet]. Annual Reviews; 2017;46:505-29. Available from: https://doi.org/10.1146/annurev-biophys-062215010822 .

21. Feldman R, Singer M, Zagoory O. Touch attenuates infants' physiological reactivity to stress. Dev Sci [Internet]. John Wiley \& Sons, Ltd (10.1111); 2010;13:271-8. Available from: https://doi. org/10.1111/j.1467-7687.2009.00890.x.

22. Stack DM, Muir DW. Tactile stimulation as a component of social interchange: new interpretations for the still-face effect. Br. J. Dev. Psychol. United Kingdom: British Psychological Society; 1990. p. 131-145.

23. Scafidi FA, Field TM, Schanberg SM, Bauer CR, Vega-Lahr N, Garcia R, et al. Effects of tactile/kinesthetic stimulation on the clinical course and sleep/wake behavior of preterm neonates. Infant Behav Dev [Internet]. 1986;9:91-105. Available from: http://www.sciencedirect.com/science/article/pii/ $016363838690041 \mathrm{X}$

24. Field TM, Schanberg SM, Scafidi F, Bauer CR, Vega-Lahr N, Garcia R, et al. Tactile/kinesthetic stimulation effects on preterm neonates. Pediatrics [Internet]. 1986;77:654 LP - 658. Available from: http://pediatrics.aappublications.org/content/77/5/654. abstract.

25. Esposito G, Yoshida S, Ohnishi R, Tsuneoka Y, Rostagno M del $\mathrm{C}$, Yokota $\mathrm{S}$, et al. Infant calming responses during maternal carrying in humans and mice. Curr Biol [Internet]. 2013;23:739-45. Available from: http://www.sciencedirect.com/science/article/pii/ S0960982213003436.

26. Caldji C, Diorio J, Meaney MJ. Variations in maternal care in infancy regulate the development of stress reactivity. Biol Psychiatry [Internet]. 2000;48:1164-74. Available from: http:/ www.sciencedirect.com/science/article/pii/S0006322300010842.

27. Liu D, Diorio J, Tannenbaum B, Caldji C, Francis D, Freedman A, et al. Maternal care, hippocampal glucocorticoid receptors, and hypothalamic-pituitary-adrenal responses to Stress. Science (80- ) [Internet]. 1997;277:1659 LP - 1662. Available from: http://science. sciencemag.org/content/277/5332/1659.abstract.

28. Li L, Rutlin M, Abraira VE, Cassidy C, Kus L, Gong S, et al. The functional organization of cutaneous low-threshold mechanosensory neurons. Cell [Internet]. 2011;147:1615-27. Available from: https:/www.ncbi.nlm.nih.gov/pubmed/ 22196735.

29. Löken LS, Wessberg J, Morrison I, McGlone F, Olausson H. Coding of pleasant touch by unmyelinated afferents in humans. Nat Neurosci [Internet]. Nature Publishing Group; 2009;12:547. Available from: https://doi.org/10.1038/nn.2312.

30. Olausson H, Lamarre Y, Backlund H, Morin C, Wallin BG, Starck $\mathrm{G}$, et al. Unmyelinated tactile afferents signal touch and project to insular cortex. Nat Neurosci [Internet]. Nature Publishing Group; 2002;5:900. Available from: https://doi.org/10.1038/nn896.

31. Shaikh S, Nagi SS, McGlone F, Mahns DA. Psychophysical investigations into the role of low-threshold $\mathrm{C}$ fibres in non-painful affective processing and pain modulation. PLoS One [Internet].
Public Library of Science; 2015;10:e0138299-e0138299. Available from: https://www.ncbi.nlm.nih.gov/pubmed/ 26372601.

32. Ackerley R, Backlund Wasling H, Liljencrantz J, Olausson H, Johnson RD, Wessberg J. Human C-tactile afferents are tuned to the temperature of a skin-stroking caress. J Neurosci [Internet]. 2014;34:2879 LP - 2883. Available from: http://www.jneurosci. org/content/34/8/2879.abstract.

33. Essick GK, McGlone F, Dancer C, Fabricant D, Ragin Y, Phillips N, et al. Quantitative assessment of pleasant touch. Neurosci Biobehav Rev [Internet]. 2010;34:192-203. Available from: http://www.sciencedirect.com/science/article/pii/ S0149763409000190.

34. Gordon I, Voos AC, Bennett RH, Bolling DZ, Pelphrey KA, Kaiser MD. Brain mechanisms for processing affective touch. Hum Brain Mapp [Internet]. John Wiley \& Sons, Ltd; 2013;34: 914-22. Available from: https://doi.org/10.1002/hbm.21480.

35. Voos AC, Pelphrey KA, Kaiser MD. Autistic traits are associated with diminished neural response to affective touch. Soc Cogn Affect Neurosci [Internet]. 2012/03/05. Oxford University Press; 2013;8:378-86. Available from: https://www.ncbi.nlm.nih.gov/ pubmed/22267520.

36. Brothers L. The neural basis of primate social communication. Motiv Emot [Internet]. 1990;14:81-91. Available from: https:// doi.org/10.1007/BF00991637.

37. Bai L, Lehnert BP, Liu J, Neubarth NL, Dickendesher TL, Nwe $\mathrm{PH}$, et al. Genetic identification of an expansive mechanoreceptor sensitive to skin stroking. Cell. 2015.

38. Wellnitz SA, Lesniak DR, Gerling GJ, Lumpkin EA. The regularity of sustained firing reveals two populations of slowly adapting touch receptors in mouse hairy skin. J Neurophysiol. 2010.

39. Liu Q, Vrontou S, Rice FL, Zylka MJ, Dong X, Anderson DJ. Molecular genetic visualization of a rare subset of unmyelinated sensory neurons that may detect gentle touch. Nat Neurosci [Internet]. 2007;10:946+. Available from: http://link.galegroup. com $/ \mathrm{apps} / \mathrm{doc} / \mathrm{A} 186823057 / \mathrm{AONE}$ ?u=upenn_main\&sid= AONE\&xid=a24d4a7f.

40. Vrontou S, Wong A, Rau K, Koerber H, Anderson D. Genetic identification of $\mathrm{C}$ fibres that detect massage-like stroking of hairy skin in vivo. Nature. 2013;493:669.

41. Olausson H, Wessberg J, Morrison I, McGlone F, Vallbo A. The neurophysiology of unmyelinated tactile afferents. Neurosci Biobehav Rev. 2010.

42. Liljencrantz $\mathrm{J}$, Olausson $\mathrm{H}$. Tactile $\mathrm{C}$ fibers and their contributions to pleasant sensations and to tactile allodynia. Front Behav Neurosci. 2014.

43. Olson W, Abdus-Saboor I, Cui L, Burdge J, Raabe T, Ma M, et al. Sparse genetic tracing reveals regionally specific functional organization of mammalian nociceptors. Elife. 2017.

44. Abdo H, Calvo-Enrique L, Lopez JM, Song J, Zhang M-D, Usoskin D, et al. Specialized cutaneous Schwann cells initiate pain sensation. Science (80- ) [Internet]. 2019;365:695 LP 699. Available from: http://science.sciencemag.org/content/365/ 6454/695.abstract

45. Ghitani N, Barik A, Szczot M, Thompson JH, Li C, Le Pichon CE, et al. Specialized mechanosensory nociceptors mediating rapid responses to hair pull. Neuron. 2017.

46. Koltzenburg M, Stucky CL, Lewin GR. Receptive properties of mouse sensory neurons innervating hairy skin. J Neurophysiol. 1997.

47. Abraira VE, Kuehn ED, Chirila AM, Heintz N, Hughes DI, Ginty DD. The cellular and synaptic architecture of the mechanosensory dorsal horn. Cell. 2017.

48. Häring M, Zeisel A, Hochgerner H, Rinwa P, Jakobsson JET, Lönnerberg P, et al. Neuronal atlas of the dorsal horn defines its 
architecture and links sensory input to transcriptional cell types. Nat Neurosci. 2018.

49. Cui L, Miao X, Liang L, Abdus-Saboor I, Olson W, Fleming MS, et al. Identification of early RET+ deep dorsal spinal cord interneurons in gating pain. Neuron. 2016.

50. Duan B, Cheng L, Bourane S, Britz O, Padilla C, GarciaCampmany L, et al. Identification of spinal circuits transmitting and gating mechanical pain. Cell. 2014.

51. Petitjean H, Pawlowski SA, Fraine SL, Sharif B, Hamad D, Fatima T, et al. Dorsal horn parvalbumin neurons are gatekeepers of touch-evoked pain after nerve injury. Cell Rep. 2015.

52. Foster E, Wildner H, Tudeau L, Haueter S, Ralvenius WT, Jegen $\mathrm{M}$, et al. Targeted ablation, silencing, and activation establish glycinergic dorsal horn neurons as key components of a spinal gate for pain and itch. Neuron. 2015.

53. Luo W, Enomoto H, Rice FL, Milbrandt J, Ginty DD. Molecular identification of rapidly adapting mechanoreceptors and their developmental dependence on Ret signaling. Neuron. 2009.

54. Kridsada K, Niu J, Haldipur P, Wang Z, Ding L, Li JJ, et al. Roof plate-derived radial glial-like cells support developmental growth of rapidly adapting mechanoreceptor ascending axons. Cell Rep. 2018.

55. Bud Craig AD. Pain mechanisms: labeled lines versus convergence in central processing. Annu Rev Neurosci. 2003.

56. Corder G, Ahanonu B, Grewe BF, Wang D, Schnitzer MJ, Scherrer G. An amygdalar neural ensemble that encodes the unpleasantness of pain. Science (80- ) [Internet]. 2019;363:276 LP 281. Available from: http://science.sciencemag.org/content/363/ 6424/276.abstract.

57. Meda KS, Patel T, Braz JM, Malik R, Turner ML, Seifikar H, et al. Microcircuit mechanisms through which mediodorsal thalamic input to anterior cingulate cortex exacerbates pain-related aversion. Neuron. 2019.

58. Sawyer EK. Conserved patterns of trigeminal somatosensory system organization in mammals. Brain Behav Evol [Internet]. 2017;89:65-7. Available from: https://doi.org/10.1159/000460812.

59. Wang X, Bey AL, Katz BM, Badea A, Kim N, David LK, et al. Altered mGluR5-Homer scaffolds and corticostriatal connectivity in a Shank3 complete knockout model of autism. Nat Commun [Internet]. Nature Publishing Group; 2016;7:11459. Available from: https://www.ncbi.nlm.nih.gov/pubmed/27161151.

60. Han Q, Kim YH, Wang X, Liu D, Zhang Z-J, Bey AL, et al. SHANK3 deficiency impairs heat hyperalgesia and TRPV1 signaling in primary sensory neurons. Neuron [Internet]. Elsevier; 2016;92:1279-93. Available from: https://doi.org/10.1016/j. neuron.2016.11.007. This article describes how SHANK3 regulates TRPV1 function in PNS neurons, providing a potential mechanism for how pain is dysregulated in autism.

61. Boeckers TM, Bockmann J, Kreutz MR, Gundelfinger ED. ProSAP/Shank proteins - a family of higher order organizing molecules of the postsynaptic density with an emerging role in human neurological disease. J. Neurochem. 2002.

62. Ray P, Torck A, Quigley L, Wangzhou A, Neiman M, Rao C, et al. Comparative transcriptome profiling of the human and mouse dorsal root ganglia: an RNA-seq-based resource for pain and sensory neuroscience research. Pain [Internet]. 2018;159:1325-45. Available from: https:/www.ncbi.nlm.nih.gov/pubmed/ 29561359.

63. Usoskin D, Furlan A, Islam S, Abdo H, Lönnerberg P, Lou D, et al. Unbiased classification of sensory neuron types by largescale single-cell RNA sequencing. Nat Neurosci [Internet]. Nature Publishing Group, a division of Macmillan Publishers Limited. All Rights Reserved.; 2014;18:145. Available from: https://doi.org/10.1038/nn.3881.

64. Moessner R, Marshall CR, Sutcliffe JS, Skaug J, Pinto D, Vincent $\mathrm{J}$, et al. Contribution of SHANK3 mutations to autism spectrum disorder. Am J Hum Genet [Internet]. 2007;81:1289-97. Available from: http://www.sciencedirect.com/science/article/pii/ S000292970763777X.

65. Sarasua SM, Boccuto L, Sharp JL, Dwivedi A, Chen C-F, Rollins JD, et al. Clinical and genomic evaluation of 201 patients with Phelan-McDermid syndrome. Hum Genet [Internet]. 2014;133: 847-59. Available from: https://doi.org/10.1007/s00439-0141423-7.

66. Wassink TH, Piven J, Patil SR. Chromosomal abnormalities in a clinic sample of individuals with autistic disorder. Psychiatr Genet [Internet]. 2001;11. Available from: https://journals.lww.com/ psychgenetics/Fulltext/2001/06000/Chromosomal_ abnormalities_in_a_clinic_sample_of.1.aspx.

67. Antar LN, Dictenberg JB, Plociniak M, Afroz R, Bassell GJ. Localization of FMRP-associated mRNA granules and requirement of microtubules for activity-dependent trafficking in hippocampal neurons. Genes, Brain Behav. 2005.

68. Huber KM, Gallagher SM, Warren ST, Bear MF. Altered synaptic plasticity in a mouse model of fragile $\mathrm{X}$ mental retardation. Proc Natl Acad Sci. 2002.

69. He CX, Cantu DA, Mantri SS, Zeiger WA, Goel A, PorteraCailliau C. Tactile defensiveness and impaired adaptation of neuronal activity in the Fmr1 knock-out mouse model of autism. J Neurosci [Internet]. 2017;37:6475 LP - 6487. Available from: http://www.jneurosci.org/content/37/27/6475.abstract. This article provides evidence that Fmr1 KO mice have impaired adaptation in cortical sensory circuits.

70. Zhang Y, Bonnan A, Bony G, Ferezou I, Pietropaolo S, Ginger M, et al. Dendritic channelopathies contribute to neocortical and sensory hyperexcitability in Fmr1-/y mice. Nat Neurosci [Internet]. Nature Publishing Group, a division of Macmillan Publishers Limited. All Rights Reserved.; 2014;17:1701. Available from: https://doi.org/10.1038/nn.3864.

71. Williams CA, Driscoll DJ, Dagli AI. Clinical and genetic aspects of Angelman syndrome. Genet Med [Internet]. The American College of Medical Genetics; 2010;12:385. Available from: https://doi.org/10.1097/GIM.0b013e3181def138.

72. LaSalle JM, Reiter LT, Chamberlain SJ. Epigenetic regulation of UBE3A and roles in human neurodevelopmental disorders. Epigenomics [Internet]. Future Medicine Ltd; 2015;7:1213-28. Available from: https://www.ncbi.nlm.nih.gov/pubmed/ 26585570.

73. Huang H-S, Allen JA, Mabb AM, King IF, Miriyala J, TaylorBlake B, et al. Topoisomerase inhibitors unsilence the dormant allele of Ube3a in neurons. Nature [Internet]. 2011;481:185-9. Available from: https://www.ncbi.nlm.nih.gov/pubmed/ 22190039.

74. Rougeulle C, Glatt H, Lalande M. The Angelman syndrome candidate gene, UBE3AIE6-AP, is imprinted in brain. Nat Genet [Internet]. 1997;17:14-5. Available from: https://doi.org/10. 1038/ng0997-14.

75. Rougeulle C, Cardoso C, Fontés M, Colleaux L, Lalande M. An imprinted antisense RNA overlaps UBE3A and a second maternally expressed transcript. Nat Genet [Internet]. 1998;19:15-6. Available from: https://doi.org/10.1038/ng0598-15.

76. Yamasaki K, Joh K, Ohta T, Masuzaki H, Ishimaru T, Mukai T, et al. Neurons but not glial cells show reciprocal imprinting of sense and antisense transcripts of Ube3a. Hum Mol Genet [Internet]. 2003;12:837-47. Available from: https://doi.org/10. 1093/hmg/ddg106.

77. Landers M, Bancescu DL, Le Meur E, Rougeulle C, Glatt-Deeley $\mathrm{H}$, Brannan C, et al. Regulation of the large (approximately 1000 $\mathrm{kb}$ ) imprinted murine Ube3a antisense transcript by alternative exons upstream of Snurf/Snrpn. Nucleic Acids Res [Internet]. Oxford University Press; 2004;32:3480-92. Available from: https://www.ncbi.nlm.nih.gov/pubmed/15226413. 
78. Numata K, Kohama C, Abe K, Kiyosawa H. Highly parallel SNP genotyping reveals high-resolution landscape of mono-allelic Ube3a expression associated with locus-wide antisense transcription. Nucleic Acids Res [Internet]. 2010/12/03. Oxford University Press; 2011;39:2649-57. Available from: https://www.ncbi.nlm. nih.gov/pubmed/21131283.

79. Walz NC, Baranek GT. Sensory processing patterns in persons with Angelman syndrome. Am J Occup Ther [Internet]. 2006;60:472-9. Available from: https://doi.org/10.5014/ajot.60. 4.472.

80. Pelc K, Cheron G, Dan B. Behavior and neuropsychiatric manifestations in Angelman syndrome. Neuropsychiatr Dis Treat [Internet]. 2008/06/. Dove Medical Press; 2008;4:577-84. Available from: https://www.ncbi.nlm.nih.gov/pubmed/ 18830393.

81. McCoy ES, Taylor-Blake B, Aita M, Simon JM, Philpot BD, Zylka MJ. Enhanced nociception in Angelman syndrome model mice. J Neurosci [Internet]. 2017;37:10230 LP - 10239. Available from: http://www.jneurosci.org/content/37/42/10230.abstract.

82. Jones RM, Cadby G, Melton PE, Abraham LJ, Whitehouse AJ, Moses EK. Genome-wide association study of autistic-like traits in a general population study of young adults. Front Hum Neurosci. 2013.

83. Krishnan V, Stoppel DC, Nong Y, Johnson MA, Nadler MJS, Ozkaynak E, et al. Autism gene Ube3a and seizures impair sociability by repressing VTA Cbln1. Nature [Internet]. Macmillan Publishers Limited, part of Springer Nature. All rights reserved.; 2017;543:507. Available from: https://doi.org/10.1038/ nature21678, 2017.

84. Matsuda K, Miura E, Miyazaki T, Kakegawa W, Emi K, Narumi $\mathrm{S}$, et al. Cbln1 is a ligand for an orphan glutamate receptor $\delta 2$, a bidirectional synapse organizer. Science (80- ). 2010.

85. Emi K, Kakegawa W, Miura E, Ito-Ishida A, Kohda K, Yuzaki M. Reevaluation of the role of parallel fiber synapses in delay eyeblink conditioning in mice using Cbln 1 as a tool. Front Neural Circuits. 2013.

86. Otsuka S, Konno K, Abe M, Motohashi J, Kohda K, Sakimura K, et al. Roles of Cbln1 in non-motor functions of mice. J Neurosci. 2016.

87. Li CL, Li KC, Wu D, Chen Y, Luo H, Zhao JR, et al. Somatosensory neuron types identified by high-coverage singlecell RNA-sequencing and functional heterogeneity. Cell Res. 2016.

88. Li C, Wang S, Chen Y, Zhang X. Somatosensory neuron typing with high-coverage single-cell RNA sequencing and functional analysis. Neurosci Bull. 2018.

89. Vrontou S, Wong AM, Rau KK, Koerber HR, Anderson DJ. Genetic identification of $\mathrm{C}$ fibres that detect massage-like stroking of hairy skin in vivo. Nature. 2013.

90. Amir RE, Van den Veyver IB, Wan M, Tran CQ, Francke U, Zoghbi HY. Rett syndrome is caused by mutations in X-linked MECP2, encoding methyl-CpG-binding protein 2. Nat Genet [Internet]. 1999;23:185-8. Available from: https://doi.org/10. $1038 / 13810$

91. Chahrour M, Sung YJ, Shaw C, Zhou X, Wong STC, Qin J, et al. $\mathrm{MeCP} 2$, a key contributor to neurological disease, activates and represses transcription. Science (80- ). 2008.

92. Leong WY, Lim ZH, Korzh V, Pietri T, Goh ELK. Methyl-CpG binding protein 2 (Mecp2) regulates sensory function through Sema5b and Robo2. Front Cell Neurosci [Internet]. Frontiers Media S.A.; 2015;9:481. Available from: https://www.ncbi.nlm. nih.gov/pubmed/26733807.
93. Devarakonda KM, Lowthian D, Raghavendra T. A case of Rett syndrome with reduced pain sensitivity. Pediatr Anesth [Internet]. John Wiley \& Sons, Ltd (10.1111); 2009;19:625-7. Available from: https://doi.org/10.1111/j.1460-9592.2009.03018.x.

94. Downs J, Géranton SM, Bebbington A, Jacoby P, Bahi-Buisson N, Ravine D, et al. Linking MECP2 and pain sensitivity: the example of Rett syndrome. Am J Med Genet A [Internet]. 2010;152A:1197-205. Available from: https://www.ncbi.nlm. nih.gov/pubmed/20425824.

95. O’Leary HM, Marschik PB, Khwaja OS, Ho E, Barnes K V, Clarkson TW, et al. Detecting autonomic response to pain in Rett syndrome. Dev Neurorehabil [Internet]. Taylor \& Francis; 2017;20:108-14. Available from: https://doi.org/10.3109/ 17518423.2015.1087437.

96. Bhattacherjee A, Mu Y, Winter MK, Knapp JR, Eggimann LS, Gunewardena SS, et al. Neuronal cytoskeletal gene dysregulation and mechanical hypersensitivity in a rat model of Rett syndrome. Proc Natl Acad Sci [Internet]. 2017;114:E6952 LP-E6961. Available from: http://www.pnas.org/content/114/33/E6952. abstract. This article provides evidence that an ASD-related gene plays a role in axon outgrowth and mechanosensory function, which may contribute to altered sensitivity in Rett syndrome.

97. Cascio CJ, Moore D, McGlone F. Social touch and human development. Dev Cogn Neurosci [Internet]. 2018; Available from: https://doi.org/10.1016/j.den.2018.04.009 VN - readcube.com. This review discusses how social touch is defined and how it can impact development.

98.•• Orefice LL, Zimmerman AL, Chirila AM, Sleboda SJ, Head JP, Ginty DD. Peripheral mechanosensory neuron dysfunction underlies tactile and behavioral deficits in mouse models of ASDs. Cell [Internet]. 2016/06/09. 2016;166:299-313. Available from: https://www.ncbi.nlm.nih.gov/pubmed/27293187. This article presents the first evidence from mouse models that deficits in peripheral sensory neurons can contribute to ASD symptoms.

99.• Orefice LL, Mosko JR, Morency DT, Wells MF, Tasnim A, Mozeika SM, et al. Targeting peripheral somatosensory neurons to improve tactile-related phenotypes in ASD models TL - 178. Cell [Internet]. 2019;178 VN-readcube.com:867. Available from: https://doi.org/10.1016/j.cell.2019.07.024. This article provides preclinical evidence that treatment with a peripherally restricted $\mathrm{GABA}_{\mathrm{A}}$ receptor agonist in multiple ASD mouse models can improve some ASD-related behaviors.

100. Groeneveld GJ, Hay JL, Van Gerven JM. Measuring blood-brain barrier penetration using the NeuroCart, a CNS test battery. Drug Discov Today Technol [Internet]. 2016;20:27-34. Available from: http://www.sciencedirect.com/science/article/pii/ S1740674916300178.

101. Broadstock M, Doughty C, Eggleston M. Systematic review of the effectiveness of pharmacological treatments for adolescents and adults with autism spectrum disorder. Autism [Internet]. SAGE Publications Ltd; 2007;11:335-48. Available from: https://doi. org/10.1177/1362361307078132.

102. Grandin T. Visual abilities and sensory differences in a person with autism. Biol Psychiatry. 2009.

Publisher's Note Springer Nature remains neutral with regard to jurisdictional claims in published maps and institutional affiliations. 